\title{
Stable Emission of $\mathrm{SnO}_{2}$ Nanowires Array at Low Field
}

\author{
Lingjie Wang, ${ }^{1,2}$ Jinyang Lin, ${ }^{1}$ Yun Ye, ${ }^{1}$ and Tailiang Guo ${ }^{1}$ \\ ${ }^{1}$ College of Physics and Information Engineering, Fuzhou University, Fuzhou 350002, China \\ ${ }^{2}$ Department of Mathematics and Physics, Xiamen University of Technology, Xiamen 361024, China
}

Correspondence should be addressed to Tailiang Guo, gtl_fzu@yahoo.com.cn

Received 20 July 2011; Accepted 22 August 2011

Academic Editors: C. Bauerle and H. Hibino

Copyright ( 2011 Lingjie Wang et al. This is an open access article distributed under the Creative Commons Attribution License, which permits unrestricted use, distribution, and reproduction in any medium, provided the original work is properly cited.

\begin{abstract}
$\mathrm{SnO}_{2}$ nanowires were synthesized by thermal evaporation, and the field emission characteristics of $\mathrm{SnO}_{2}$ nanowires are investigated in detail. The results show that the turn-on field is as low as $1.39 \mathrm{~V} / \mu \mathrm{m}$. And the fluctuation of field emission currents is as low as $2.8 \%$ for $24 \mathrm{~h}$. The results reveal that $\mathrm{SnO}_{2}$ nanowires hold promise for field emission display application.
\end{abstract}

\section{Introduction}

Great attention has been paid to one dimensional nanomaterials, such as carbon nanotubes (CNTs), $\mathrm{SiC}, \mathrm{ZnO}, \mathrm{SnO}_{2}$, $\mathrm{CuO}$, and AlN [1-7]. They are considered to be ideal cold cathode materials because the high aspect ratio of onedimensional nanostructure contributes to field emission. $\mathrm{SnO}_{2}$, which is an n-type semiconductor with wide-band gap (3.6 ev), exhibits fascinating electric characteristics and high chemical and thermal stability. Recently some studies have focused on field emission properties of various nanostructures of $\mathrm{SnO}_{2}$, implying that it would have a potential application in field emitter [8-11]. However there are few reports specialized on its emission stability. In this work, $\mathrm{SnO}_{2}$ nanowires were synthesized by thermal evaporation. The morphology investigation and field emission measurement revealed that the $\mathrm{SnO}_{2}$ nanowires exhibit excellent field emission property at low turn on electric field.

\section{Experiment}

The experiment was carried out in a horizontal electronic resistance furnace. A ceramic boat with Sn powder spread on it was placed at the centre of the furnace. And a stainless steel mesh with pore diameters of $500 \mu \mathrm{m}$ was placed $5 \mathrm{~cm}$ far away from the source along the down airflow to collect the product. The furnace was quickly heated to $950^{\circ} \mathrm{C}$, and then oxygen gas was introduced at a rate of $10 \operatorname{SCCM}\left(\mathrm{cm}^{3} / \mathrm{min}\right)$. After 30 minutes' reaction, the system was shut down and cooled down to room temperature. Some white wool-like products were found on the mesh.

The morphology observation was performed by scanning electron microscopy (SEM) (Hitachi-S3000N) and X-ray diffraction (XRD, D/Max $-\gamma \mathrm{A}$, and $\mathrm{CuK} \alpha$ radiation). Field emission measurements of $\mathrm{SnO}_{2}$ nanowires were performed in a vacuum chamber under a pressure of $2 \times 10^{-4} \mathrm{~Pa}$ at room temperature. The anode was an indium tin oxide (ITO)-coated glass, and the cathode was the as-synthesized $\mathrm{SnO}_{2}$ samples on stain steel mesh. They were separated by a space of $1 \mathrm{~mm}$ in height.

\section{Results and Discussion}

Figure 1 show the SEM image of $\mathrm{SnO}_{2}$ nanowires synthesized at $950^{\circ} \mathrm{C}$. The pictures indicate that $\mathrm{SnO}_{2}$ are grown upward on the stainless steel mesh, and the nanowires have perfect dimensional uniformity. The average diameters of the nanowires is about $180 \mathrm{~nm}$; however, the length reachs up to tens of micrometers. As shown in Figure 2, the XRD spectrum detached from the substrate indicates that the nanowires are tetragonal rutile structure with the lattice constants of $a=b=0.443 \mathrm{~nm}$ and $c=0.372 \mathrm{~nm}$, which correspond with the data of $\mathrm{SnO}_{2}$ powders recorded in the JCPDS document (powder diffraction file compiled by the joint Committee on Powder Diffraction, 1985, Card No. 031116). No other impurities were detected.

The growth of $\mathrm{SnO}_{2}$ nanowires can be explained by the vapour-solid (VS) mechanism. When the temperature 


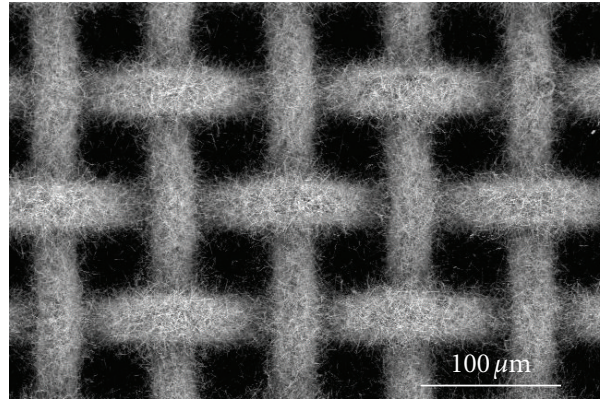

(a)

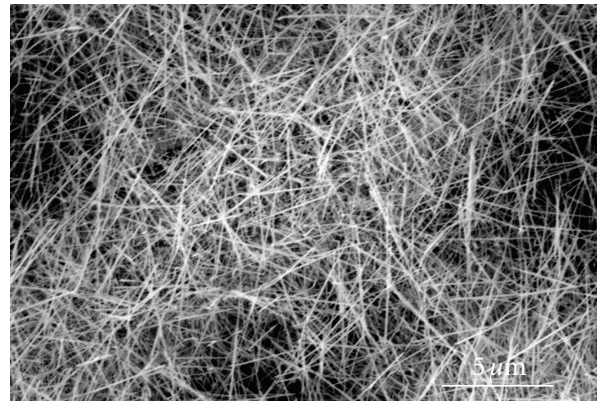

(b)

Figure 1: (a) Top view of $\mathrm{SnO}_{2}$ nanowires. (b) The enlarged magnification SEM image of nanowires.

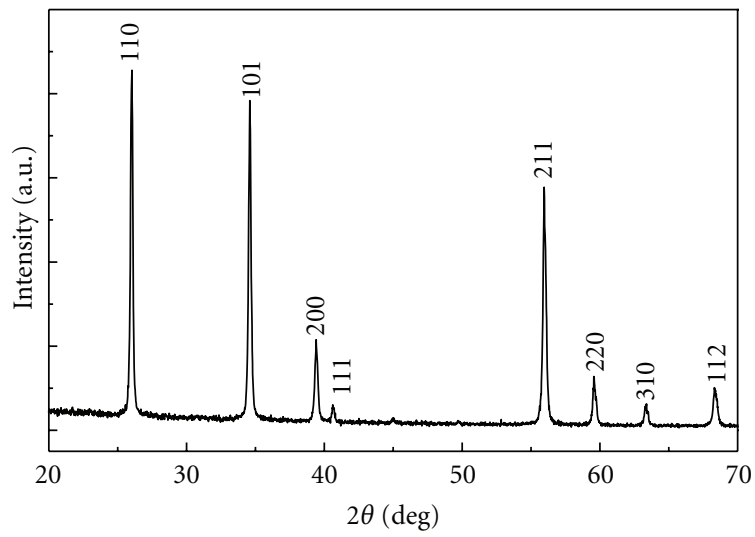

FIgURE 2: The XRD patterns of $\mathrm{SnO}_{2}$ nanowires.

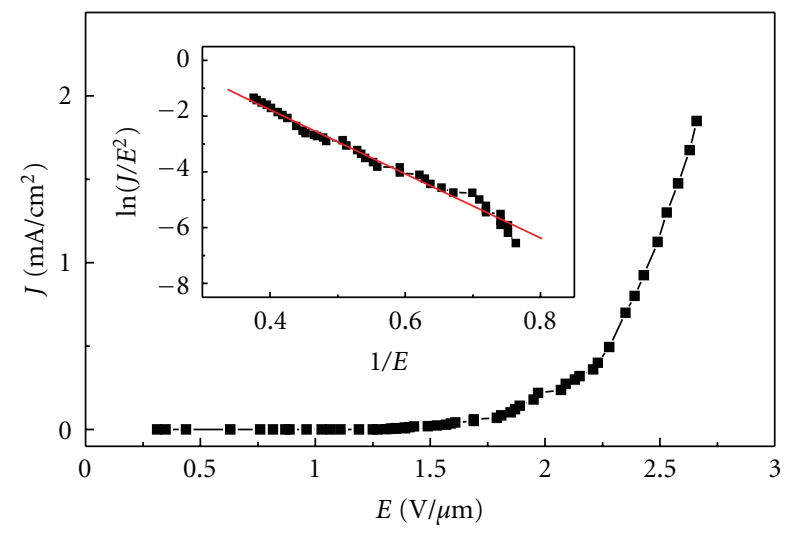

(a)

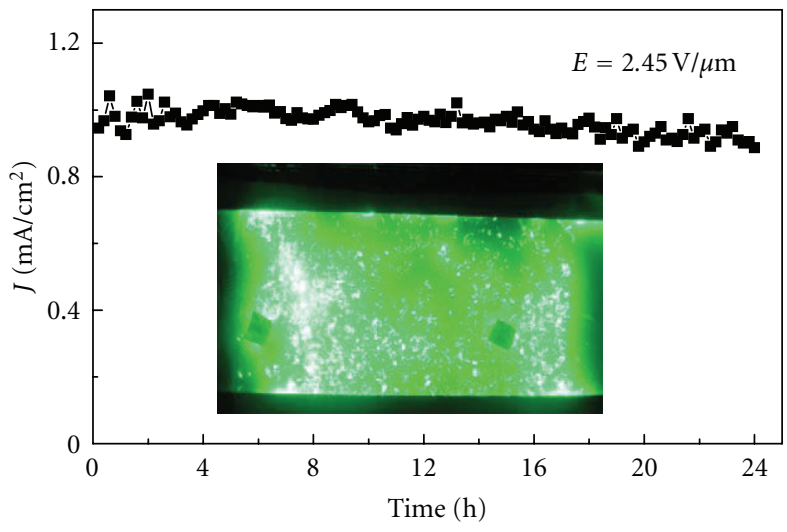

(b)

Figure 3: (a) $J$-E characteristics of $\mathrm{SnO}_{2}$ nanowires. The inset shows the F-N plot. (b) Stability curve at an applied field of $2 \mathrm{~V} / \mu \mathrm{m}$. The insert is field emission photograph of $\mathrm{SnO}_{2}$ nanowires.

reached to the peak, the oxygen combined with Sn vapour and then deposited on the substrate. The substrate may have some catalyzation, and it is very easy for $\mathrm{SnO}_{2}$ to grow on it. During the system cooling down, there was still many $\mathrm{Sn}$ or $\mathrm{SnO}$ vapour surrounding the substrate.

The emitting current density versus the electric field ( $J$ $E$ ) plot is shown in Figure 3(a). The turn-on field, which is defined as required electric field when current density comes to $10 \mathrm{uA} / \mathrm{cm}^{2}$, is observed to have only $1.39 \mathrm{~V} / \mu \mathrm{m}$. And the threshold field (defined as the field where the current density reaches to $1 \mathrm{~mA} / \mathrm{cm}^{2}$ ) is $2.45 \mathrm{~V} / \mu \mathrm{m}$. The emission current elevates rapidly with the increase of the applied field. When the electric field reaches to $2.66 \mathrm{~V} / \mu \mathrm{m}$, the current density is as high as $1.85 \mathrm{~mA} / \mathrm{cm}^{2}$. The efficient electron emission from $\mathrm{SnO}_{2}$ nanowires may be due to that $\mathrm{SnO}_{2}$ can provide enough electrons. And the high length-diameter ratio of nanowires can greatly enhance the field around the cathode; thus, the turn-on field is reduced. The high current density 
results from the good electrical contact between $\mathrm{SnO}_{2}$ and the substrate.

Shown in the inset of Figure 3(a), the Fowler-Nordheim (F-N) plot exhibits approximately straight lines. It demonstrates that the emission electrons are extracted by electric field and come through the barrier tunnelling. According to F-N law, the relationship between current density $(J)$ and the applied field $(E)$ can be described as (1)

$$
J=\left(\frac{A E^{2}}{\varphi}\right) \exp \left(-\frac{B \varphi^{3 / 2}}{\beta E}\right)
$$

where $\varphi$ is the work function of the emitting material, $A$ and $B$ are constants, $1.56 \times 10^{-10} \mathrm{AV}^{-2} \mathrm{eV}$ and $6.83 \times$ $10^{9} \mathrm{VeV}^{-3 / 2} \mathrm{~m}^{-1}$, respectively. As the work function of $\mathrm{SnO}_{2}$ is $4.3 \mathrm{eV}$, we can figure out that the field enhancement factor $\beta$ is 5272 . That demonstrates that the structure of nanowires greatly enhances the electric field and promote field emission.

Figure 3(b) shows the fluctuation of current density at the field of $2.45 \mathrm{~V} / \mu \mathrm{m}$. At first, the electric current experience a short period of fluctuating, that may be due to some emitters in the condition of preemission. Then the current density tends towards stability, and the current fluctuation is about $2.8 \%$. It is regarded that the $\mathrm{SnO}_{2}$ nanowires electrons emit stably without degradation for 24 hours. The insert is the emission photograph of $\mathrm{SnO}_{2}$ nanowires at $2.45 \mathrm{~V} / \mu \mathrm{m}$. The effective light area is $1 \mathrm{~cm} \times 2 \mathrm{~cm}$, and its luminous intensity is $350 \mathrm{~cd} / \mathrm{m}^{2}$. It can be seen that the margin is a little brighter than the centre, but the luminescence is uniform on the whole.

\section{Conclusion}

In summary, $\mathrm{SnO}_{2}$ nanowires have been successfully synthesized on stainless steel mesh by thermal evaporation. The morphology and field emission investigation revealed that the turn-on field $\mathrm{SnO}_{2}$ nanowires are as low as $1.39 \mathrm{~V} / \mathrm{um}$, and the emission current density is as high as $1.85 \mathrm{~mA} / \mathrm{cm}^{2}$ at the field of $2.66 \mathrm{~V} / \mathrm{um} . \mathrm{SnO}_{2}$ nanowires exhibit good luminescent capability and excellent stability at low field. The results reveal that $\mathrm{SnO}_{2}$ nanowires potentially applied in field emission and other photoelectric devices.

\section{Acknowledgments}

This work was supported by the National High Technology Research and Development Program of China (no. 2008AA03A313) and by Open Project of Engineer Research Centre of China Education Department (no. KF1106).

\section{References}

[1] A. L. Prudnikava, B. G. Shulitski, V. A. Labunov, A. Navitski, V. Sakharuk, and G. Müller, "Efficient high-current field emission from arrays of CNT columns," in Proceedings of the 22nd International Vacuum Nanoelectronics Conference (IVNC '09), pp. 257-258, July 2009.

[2] X. X. Zhang and C. C. Zhu, "Electron translocation and field emission in printed CNT film by high-temperature sintering and post-treatment," Microelectronics Journal, vol. 40, no. 8, pp. 1166-1169, 2009.

[3] K. Wong, X. Zhou, F. C. K. Au et al., "Field emission characteristics of $\mathrm{SiC}$ nanowires prepared by chemical vapour deposition," Applied Physics Letters, vol. 75, no. 20, pp. 29182920, 1999.

[4] A. Qurashi, J. H. Kim, and Y. B. Hahn, "Density-controlled selective growth of well-aligned $\mathrm{ZnO}$ nanorod arrays by a hybrid approach," Superlattices and Microstructures, vol. 48, no. 2, pp. 162-169, 2010.

[5] Z. Li, H. Wang, and Z. Qin, "A rapid and efficient method to prepare aligned $\mathrm{SnO}_{2}$ nanorod arrays for field-emission application," Vacuum, vol. 83, no. 11, pp. 1340-1343, 2009.

[6] C. T. Hsieh, J. M. Chen, H. H. Lin, and H. C. Shih, "Field emission from various Cuo nanostructures," Applied Physics Letters, vol. 83, no. 16, pp. 3383-3385, 2003.

[7] Y. B. Tang, H. T. Cong, Z. M. Wang, and H. M. Cheng, "Catalyst-seeded synthesis and field emission properties of flowerlike Si-doped AlN nanoneedle array," Applied Physics Letters, vol. 89, no. 25, Article ID 253112, 2006.

[8] Z. Li, H. Wang, P. Liu, B. Zhao, and Y. Zhang, "Synthesis and field-emission of aligned $\mathrm{SnO}_{2}$ nanotubes arrays," Applied Surface Science, vol. 255, no. 8, pp. 4470-4473, 2009.

[9] Y. Zhang, K. Yu, G. Li et al., "Synthesis and field emission of patterned $\mathrm{SnO}_{2}$ nanoflowers," Materials Letters, vol. 60, no. 2526, pp. 3109-3112, 2006.

[10] Y. J. Chen, Q. H. Li, Y. X. Liang, T. H. Wang, Q. Zhao, and D. P. $\mathrm{Yu}$, "Field-emission from long $\mathrm{SnO}_{2}$ nanobelt arrays," Applied Physics Letters, vol. 85, no. 23, pp. 5682-5684, 2004.

[11] Q. Wang, K. Yu, and F. Xu, "Synthesis and field emission of two kinds of hierarchical $\mathrm{SnO}_{2}$ nanostructures," Solid State Communications, vol. 143, no. 4-5, pp. 260-263, 2007. 

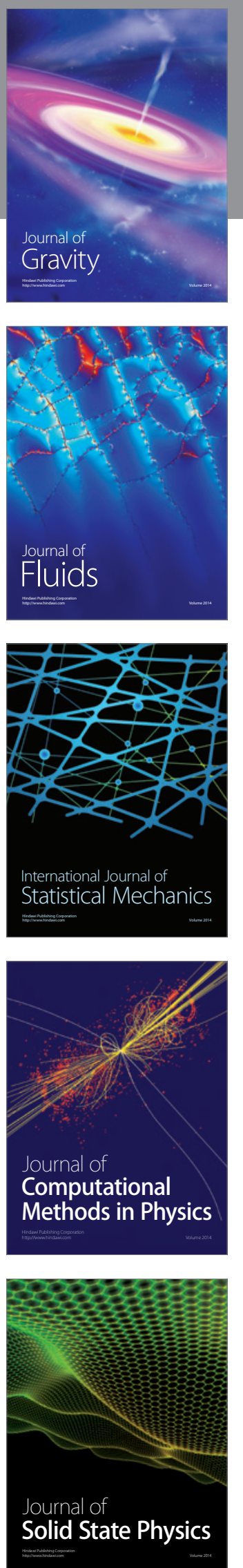
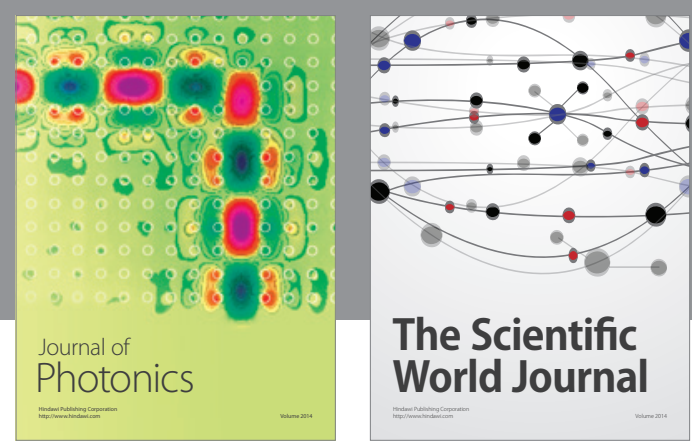

The Scientific World Journal

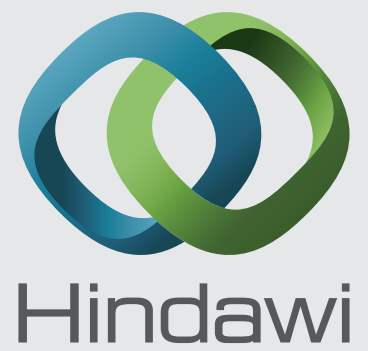

Submit your manuscripts at http://www.hindawi.com
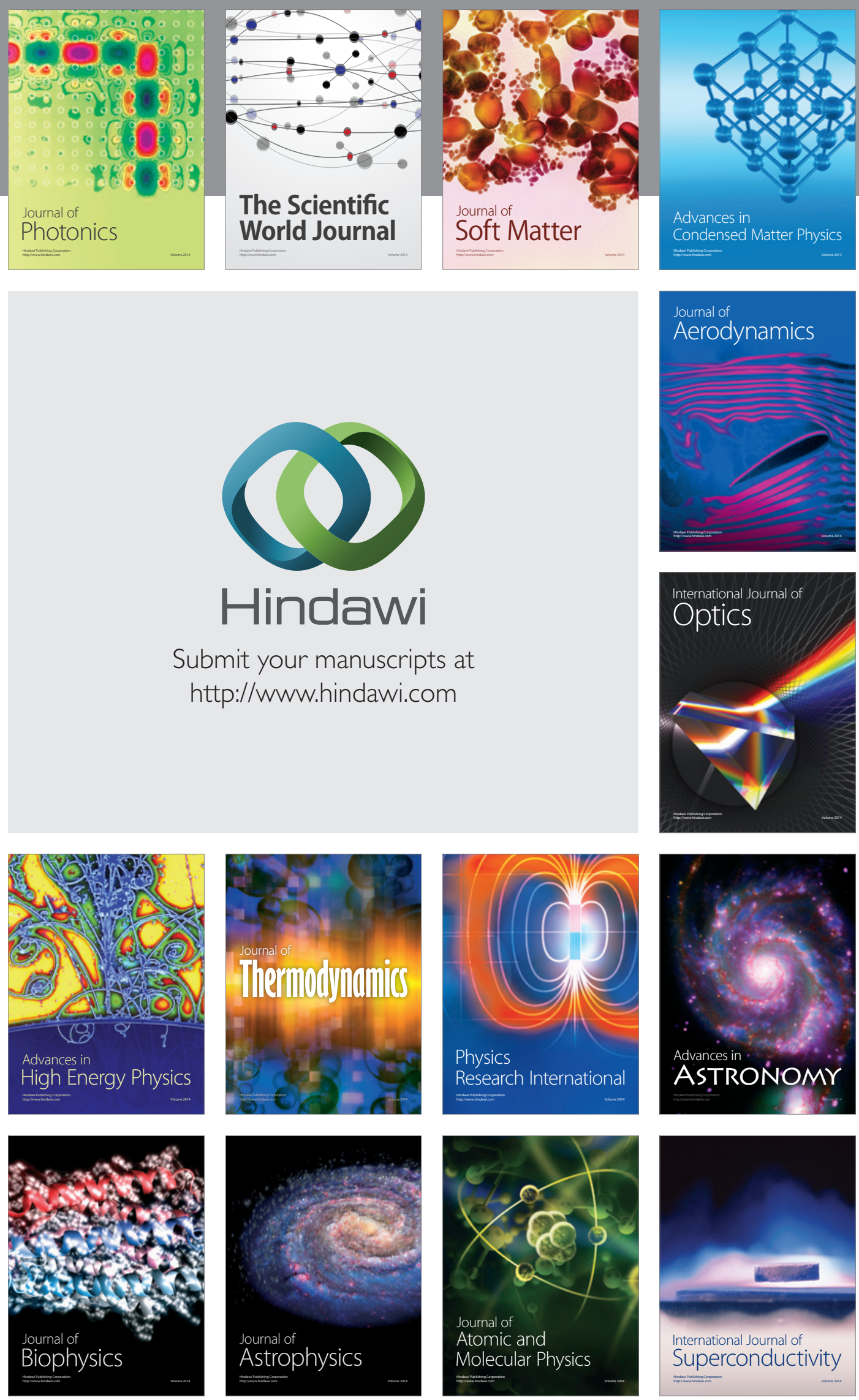
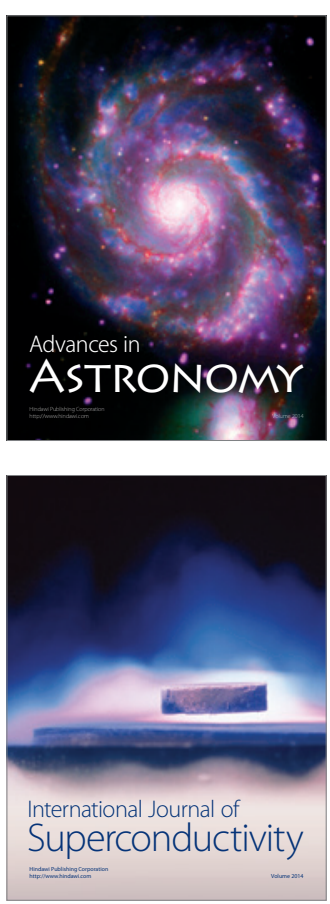